\title{
CONTRIBUIÇÃO DO FOMENTO DO ÓRGÃO FLORESTAL DE MINAS GERAIS PARA A ZONA DA MATA
}

\author{
Sidney Araujo Cordeiro - Doutorando em Ciência florestal, Universidade Federal de Viçosa, \\ sidney.cordeiro@ufv.br \\ Márcio Lopes da Silva - Professor do Departamento de Engenharia Florestal, Universidade Federal de Viçosa, \\ marlosil@ufv.br \\ José Ludgero Rocha - Engenheiro Florestal, Pesquisador do Instituto Estadual de Florestas - IEF/MG, \\ Belo Horizonte, MG, ludgerorocha@yahoo.com.br \\ Laércio Antônio Gonçalves Jacovine - Professor do Departamento de Engenharia Florestal, \\ Universidade Federal de Viçosa, jacovine@ufv.br \\ Sebastião Renato Valverde - Professor do Departamento de Engenharia Florestal da Universidade Federal de Viçosa, \\ valverde@ufv.br
}

\section{RESUMO}

Este estudo analisou o desempenho do fomento florestal do Instituto Estadual de Florestas (IEF/MG), para a regional Mata, procurando identificar os benefícios e os aspectos a serem melhorados. O trabalho foi realizado com base em dados sobre a regional, fornecidos pelo IEF/MG e por produtores atendidos pelo seu programa de fomento. Foram utilizados 12 indicadores de desempenho, definidos através de reuniões com técnicos do referido órgão. Os dados foram avaliados por meio da análise tabular e em gráficos de médias aritméticas. Os núcleos de Viçosa e Juiz de Fora obtiveram o melhor resultado, juntos sendo responsáveis por $57 \%$ do desempenho. A estimativa do número de empregos gerados pelos reflorestamentos em 2006 foi de 452 empregos. Concluiuse também que há necessidade de um maior número de técnicos envolvidos com a atividade de fomento florestal.

Palavras chaves: fomento florestal; extensão florestal; Minas Gerais.

\section{INTRODUÇÃO}

O fomento florestal é um instrumento estratégico que promove a integração dos produtores rurais à cadeia produtiva e lhes proporciona vantagens econômicas, sociais e ambientais. Como atividade complementar na propriedade rural, viabiliza o aproveitamento de áreas degradadas, improdutivas, subutilizadas e inadequadas à agropecuária, propiciando alternativa adicional de renda ao produtor rural (Siqueira et al., 2004; Canto et al., 2007).

Os programas de fomento florestal praticados pelo Instituto Estadual de Florestas (IEF/ MG) buscam encontrar uma maneira de atender a essa demanda industrial e doméstica, respeitando as áreas de preservação permanente e de reserva legal. É um incentivo à produção de madeira através do fornecimento de mudas, assistência técnica e insumos a produtores rurais cadastrados. Os projetos são executados pelos próprios produtores em suas terras utilizando mão-de-obra própria (Ief, 2007).

No fomento promovido pelo estado (IEF), o produtor recebe mudas, assistência técnica, formicida, adubo etc. Não tem compromisso com a venda da madeira, ou seja, esta é vendida da maneira que melhor lhe convier e no momento em que ele achar mais indicado. Este fomento é muito interessante para o produtor, pois não há contrato. Se o reflorestamento é viável, mesmo sendo feito com recurso próprio, mais lucrativo ele será quando feito com os incentivos do fomento do IEF. 
A estrutura descentralizada do IEF apóia-se em treze escritórios regionais, com seus respectivos núcleos e centros administrativos. Esses têm por finalidade planejar, supervisionar, orientar e executar, no âmbito da respectiva região, as atividades relativas à política florestal do estado, à preservação da flora e da fauna, ao desenvolvimento sustentável da pesca e dos recursos naturais renováveis no estado, e à realização e difusão de pesquisa em biomassa e biodiversidade.

A participação dos pequenos e médios produtores rurais é de fundamental importância para a atividade florestal integrada ao consumo industrial. Os reflorestamentos nas pequenas e médias propriedades rurais, advindos ou não de programas de fomento, apresentam maior probabilidade de sustentabilidade na medida em que geram benefícios sociais mais amplos e mitigam impactos ambientais negativos (Oliveira, 2006).

\section{OBJETIVO}

Com base no exposto, este trabalho teve como objetivo analisar o desempenho do fomento florestal com eucalipto realizado pelo IEF/ MG, para a regional Mata, no período de 1989 a 2006, procurando identificar os benefícios e os aspectos a serem melhorados neste fomento.

\section{MATERIAL E MÉTODOS}

\section{Área de Estudo}

O presente trabalho foi realizado dentro da Zona da Mata de Minas Gerais com proprietários rurais contemplados pelo seu programa de fomento, no período de 1989 a 2006.

Tabela 1. Regionais do IEF/MG com seus respectivos núcleos e centros operacionais.

\begin{tabular}{|c|l|}
\hline Regionais & \multicolumn{1}{|c|}{ Núcleos e Centros Operacionais } \\
\hline Alto Jequitinhonha & Capelinha, Itamarandiba, Serro \\
\hline Alto Médio S. Francisco & Jaíba, São Francisco, São Romão \\
\hline Alto Paranaíba & Araxá, Patrocínio, Presidente Olegário \\
\hline Centro Norte & Curvelo, Pará de Minas, Pompéu, Sete Lagoas \\
\hline Centro Oeste & Arcos, Oliveira \\
\hline Centro Sul & $\begin{array}{l}\text { Belo Horizonte, Conselheiro Lafaiete, João Monlevade, S. João } \\
\text { Del Rei }\end{array}$ \\
\hline Mata & Carangola, Juiz de Fora, Manhuaçú, Muriaé, Viçosa \\
\hline Nordeste & Itambacuri, Jequitinhonha, Medina, Nanuque \\
\hline Noroeste & Arinos, João Pinheiro, Paracatu \\
\hline Norte & Bocaiúva, Janaúba, Pirapora, Salinas \\
\hline Rio Doce & Caratinga, Conselheiro Pena, Guanhães, Timóteo \\
\hline Sul & Caxambu, Lavras, Passos, Possos de Caldas, Pouso Alegre \\
\hline Triângulo & Araguari, Ituiutaba, Iturama, Uberaba \\
\hline
\end{tabular}

A Regional Mata foi escolhida para análise de forma mais detalhada, devido à maior disponibilidade de dados por ano civil, desde 1989 até 2006. A sede do Escritório Regional Mata fica localizada em Ubá. A regional possui 20 Aflobios atendendo a toda a Zona da Mata com uma área de $35.555 \mathrm{~km} 2$, abrangendo 142 municípios. Possui 5 núcleos operacionais: Juiz de Fora (atendendo a 37 municípios), Carangola (atendendo a $11 \mathrm{mu}-$ nicípios), Manhuaçu (atendendo a 24 municípios), Muriaé (atendendo a 26 municípios) e Viçosa (atendendo a 44 municípios) (Cordeiro, 2008).

\section{Fonte de dados}

O trabalho foi realizado com dados referentes ao fomento florestal com eucalipto (por ano civil, 1989 - 2006) referentes ao nú- 
mero de mudas produzidas, número de mudas plantadas, área plantada, quantidade de insumos distribuídos, fomentados cadastrados e visitados pelos técnicos, área de floresta plantada pelo fomento do IEF/MG, área colhida de florestas plantadas (para o ano de 2006), destino e quantificação do material lenhoso $\left(\mathrm{m}^{3}\right)$ (para o ano de 2006), para a regional Mata. Todas as informações foram obtidas nos escritórios do IEF/MG e junto a proprietários rurais que participam dos programas de fomento florestal do IEF/MG.

\section{Indicadores de desempenho}

Para verificar o desempenho das regionais com relação ao programa de fomento, foram utilizados 12 indicadores de desempenho, tendo cada um recebido o mesmo peso.

Esses indicadores foram obtidos através de dados fornecidos pelo IEF (1989-2006) e escolhidos através de reuniões com seus técnicos. São eles:

- número de mudas produzidas pelas regionais do IEF/MG;

- número de mudas plantadas nas regionais do IEF/MG;

- área plantada (ha) pelo fomento do IEF/MG;

- extensão territorial das regionais $\left(\mathrm{km}^{2}\right)$ do IEF/MG;

- número de municípios das regionais do IEF/ MG;

- número de fomentados que receberam mudas pelo IEF/MG;

- número de fomentados que receberam insumos (adubo e formicida) pelo IEF/MG;

- número de fomentados cadastrados pelos técnicos do IEF/MG;

- número de fomentados visitados pelos técnicos do IEF/MG;

- quantidade (ton.) de insumos (adubo e formicida) fornecidos pelo IEF/MG aos produtores;

- índice de assistência técnica (IAT) $=\mathrm{n}^{\circ}$ de fomentados visitados $/ \mathrm{n}^{\mathrm{o}}$ de fomentados que receberam mudas; e
- índice de cadastro (IC), sendo IC $=n^{0}$ de produtores cadastrados $/ \mathrm{n}^{\mathrm{o}}$ de fomentados que receberam mudas.

\section{Análise dos dados}

Os dados foram analisados por meio da análise tabular e dos gráficos de médias aritméticas. Essa técnica facilita a compreensão dos dados qualitativos e permite a descrição pormenorizada das variáveis estudadas (Mata, 1994).

O cálculo do desempenho geral das regionais foi realizado da seguinte forma: obteve-se as médias de cada indicador para cada regional, obtendo-se assim, a participação percentual $(\%)$ de cada regional nos indicadores utilizados. Obteve-se então a soma dos percentuais dos indicadores para cada regional, procedendo-se ao cálculo das médias totais. Com isso, obteve-se o percentual de desempenho de cada regional do IEF/MG.

Para determinar a quantidade de mãode-obra utilizada no reflorestamento, tomouse por base o trabalho de Fontes (2001) na região de Viçosa - MG, onde o reflorestamento utilizou, em média, 105,10 dias.homem/ ha, considerando todas as fases, tendo a implantação necessitado de 30,21 dias.homem/ ha $(28,74 \%)$, a manutenção de 13,64 dias.ho$\mathrm{mem} / \mathrm{ha}(12,98 \%)$ e a colheita de 61,25 dias. homem/ha $(58,28 \%)$.

\section{RESULTADOS}

\section{Desempenho da Regional Mata (1989-2006)}

A Regional Mata foi escolhida para análise de forma mais detalhada, devido à maior disponibilidade de dados por ano civil.

\section{Mudas plantadas e área plantada}

O fomento florestal realizado pelo IEF, na Regional Mata durante 1989 a 2006, registra 
um número de 50.333.000 mudas plantadas. No período entre 1989 e 1995, os dados totalizam 18.876.000 mudas plantadas (Figura 1).

A partir de 1996, pode-se observar a evolução do número de mudas plantadas pelo fomento do IEF, através da Figura 1. Em 1996 foram plantadas 2.861 .000 mudas. Nos anos 1997, 1998 e 1999, observa-se uma queda, sendo o número de mudas plantadas de $2.851 .000,2.219 .000$ e 1.434 .000 , respectivamente. O ano de 1999 foi o ano em que se plantou o menor número de mudas. $\mathrm{O}$ ano de 2003 foi o ano em que se plantou mais na Regional Mata, 4.414.000 mudas.

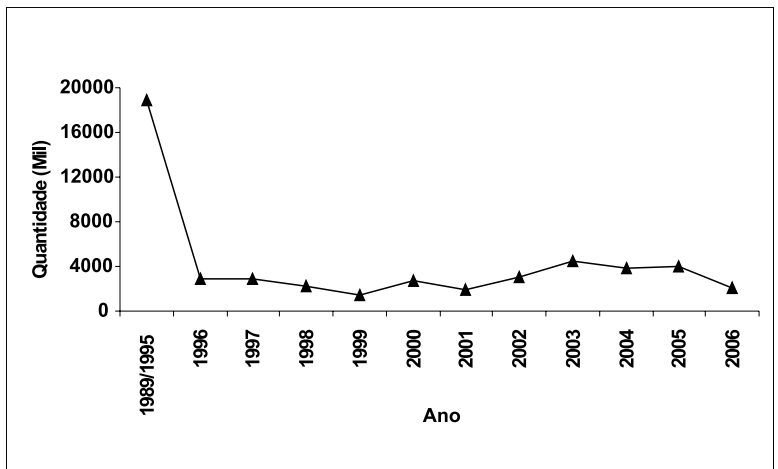

Figura 1. Quantidade de mudas plantadas por produtores fomentados pelo IEF, na Regional Mata, ao longo do período 1989-2006.

Pode-se observar, na Figura 2, que no período entre 1989 e 1995 foi registrada uma área total de 9.106 ha de florestas de Eucalipto plantadas por produtores fomentados pelo IEF. O ano de 1999 foi o ano em que se plantou a menor área de florestas pelo fomento do IEF na Regional Mata. Como visto na Figura 1, o ano de 2003 foi o ano em que se plantou mais na Regional Mata, 4.414.000 mudas numa área de 2.603ha.

\section{Produtores fomentados e assistência técnica}

Ao longo dos anos de 1989 a 2006, o IEF fomentou 11.347 produtores com mudas de eucalipto na Regional Mata. No período compreendido entre 1989 e 1995, foram 4.087 fomentados com mudas. Analisando a partir de 1996, o ano de 2002 foi aquele em que o IEF mais forneceu mudas, sendo 1.093 fomentados. Já o ano de 2004 foi o ano em que houve o menor número de fomentados, 407 (Figura 3). Analisando a Figura 3, pode-se observar que o número de fomentados visitados pelos técnicos do IEF, sempre foi menor do que o número de fomentados que receberam mudas, caracterizando uma defasagem na assistência a esses fomentados. Essa defasagem foi de 2.462 fomentados para o período 1989 a 1995. Os anos que apresentaram maior defasagem foram 1996 e 2002, com 517 e 520 fomentados que não foram visitados. Os anos que apresentaram menor defasagem foram $2001 \mathrm{e}$ 2006, com 121 e 120 fomentados que não foram visitados.

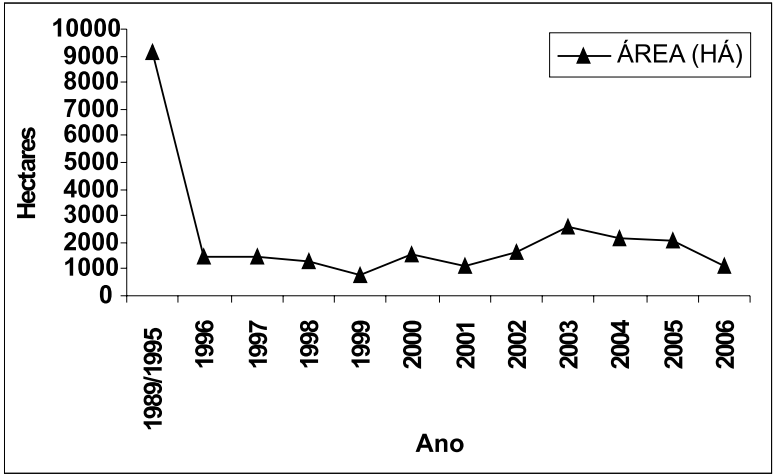

Figura 2. Área plantada por produtores fomentados pelo fomento de IEF na Regional Mata, ao longo do período 1989-2006.

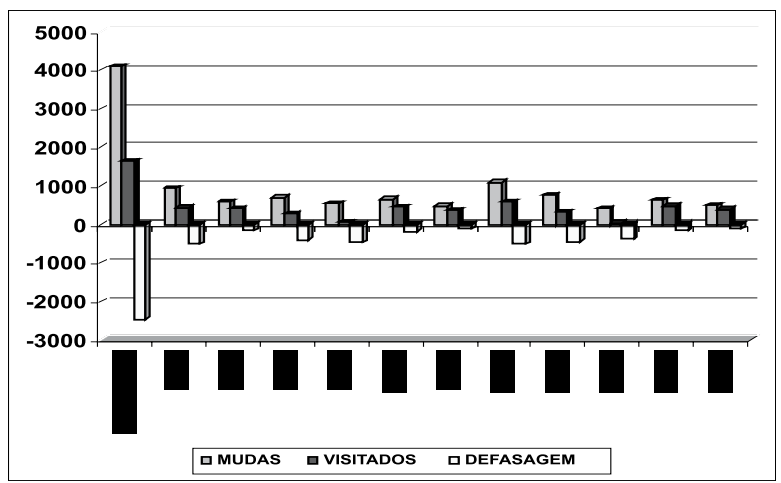

Figura 3. Número de produtores que receberam mudas, visitados, e defasagem de visitados, pelo fomento de IEF na Regional Mata, ao longo do período entre 1989-2006. 
Assim como as demais Regionais do IEF, a Regional Mata, ao longo desses anos, sempre apresentou índices de assistência técnica (IAT) baixos, visto que o ideal seriam 3 visitas ao fomentado, sendo uma na implantação e as demais no decorrer do crescimento da floresta e na época de corte. No período entre 1989 e 1995, a média do IAT foi de 0,4. A partir de 1996, observa-se que os anos em que se obteve maior IAT foram 2005 e 2006, sendo de 0,8 (Figura 4).

Na Figura 5, tem-se a média dos índices de assistência técnica (IAT) ao longo do período de 1989 a 2006, em que todos os núcleos apresentam baixos valores, sendo Juiz de Fora o melhor núcleo com IAT de 0,78, ou seja, menos de uma visita em média por fomentado.

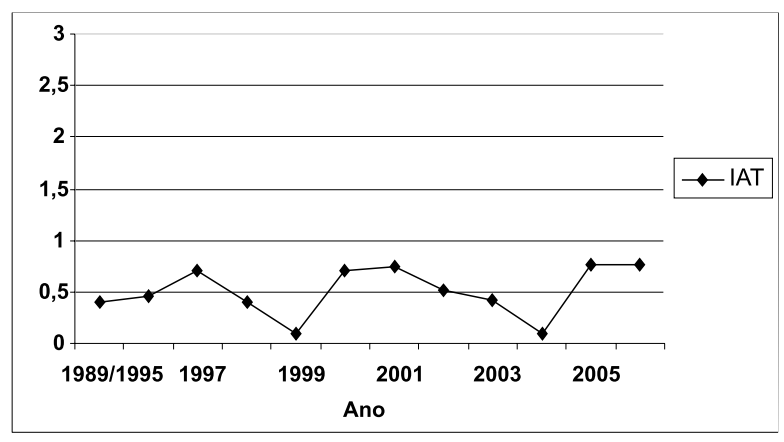

Figura 4. Evolução do Índice de Assistência Técnica por parte do IEF, para a Regional Mata, no período entre 1989-2006.

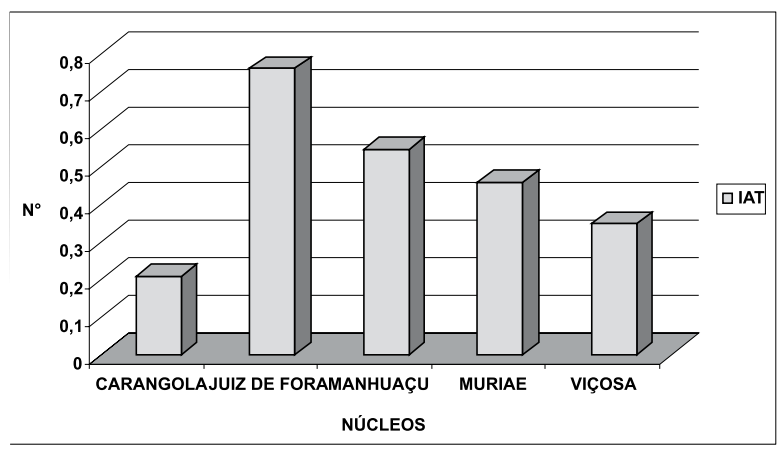

Figura 5. Índices de Assistência Técnica por parte do IEF, para os núcleos da Regional Mata, no período 1989-2006.

\section{Desempenho geral}

Dentre os núcleos da Regional Mata, no período de 1989 a 2006, Viçosa destaca-se com o melhor desempenho, com 4,2\%, seguida por Juiz de Fora com 2,62\%, Muriaé com $2,23 \%$ e Carangola com 1,49\% (Figura 6).

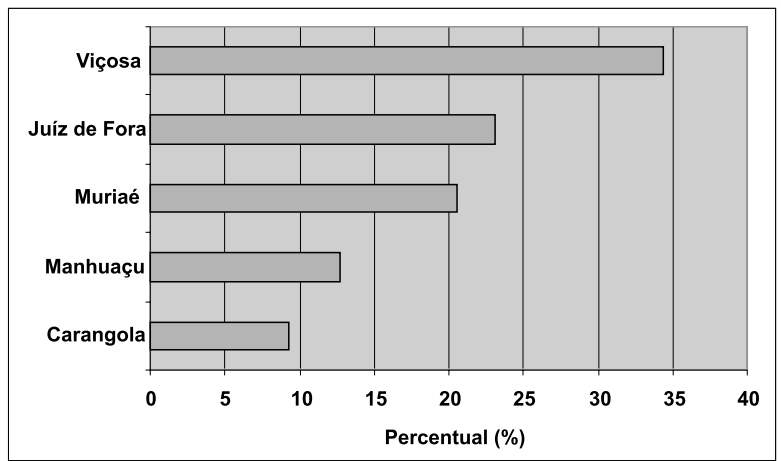

Figura 6. Desempenho dos núcleos da regional Mata no programa de fomento florestal do IEF, no período 1989-2006.

O núcleo de Carangola, região de tradição cafeeira, obteve os menores valores para todos os indicadores, mostrando que deve ser realizado um melhor planejamento e investimento para que futuramente esse núcleo possa obter melhores indicadores.

Ao analisar o desempenho geral desses núcleos no ano de 2006, observou-se que Juiz de Fora obteve o melhor desempenho d e n tre os núcleos da Regional, com 51\%, seguido por Viçosa com $44 \%$ e por Muriaé com 5\%. É importante lembrar que não se tem registro desses indicadores para o núcleo de Carangola. Essa mudança de posição entre Viçosa e Juíz de Fora se deve ao fato de este último núcleo ter 243 fomentados que receberam mudas, número maior que o de Viçosa que teve 132 fomentados que receberam mudas em 2006, segundo registros do IEF. Conseqüentemente, o número de fomentados que receberam insumos, cadastrados e visitados, e o IAT (Índice de Assistência Técnica) foram maiores no núcleo de Juiz de Fora do que no núcleo de Viçosa.

Estima-se que tenham sido gerados cerca de 450 empregos pelos reflorestamentos 
realizados nos programas de fomento florestal do IEF, com eucalipto no ano de 2006, sendo 130 na fase de implantação da floresta, 58,7 na fase de manutenção da floresta e 263,5 na colheita da floresta.

\section{CONCLUSÕES}

- Dentre os núcleos da Regional Mata, no período de 1989 a 2006, Viçosa destaca-se com melhor desempenho. Mas em 2006, Juiz de fora obteve o melhor desempenho dentre os núcleos da Regional, seguido por Viçosa.

- O programa de fomento florestal com eucalipto, realizado pelo IEF/MG, contribui para a geração de renda e empregos nas propriedades rurais da Zona da Mata mineira.

- Pode-se concluir também que há grande deficiência com relação à assistência técnica do IEF, havendo necessidade de maior número de técnicos envolvidos com a atividade de fomento florestal.

\section{AGRADECIMENTOS}

Ao Conselho Nacional de Desenvolvimento Científico e Tecnológico $(\mathrm{CNPq})$ e à Fundação de Amparo à Pesquisa do Estado de Minas Gerais (FAPEMIG) pelo apoio financeiro; ao IEF/MG pela disponibilização dos dados; e à UFV pela infra-estrutura.

\section{REFERÊNCIAS BIBLIOGRÁFICAS}

CANTO J. L.; MACHADO C .C.; SOUZA A. P.; GARLET A.; CARVALHO R. M. M. A.; NOCE R. Avaliação das condições de segurança do trabalho na colheita e transporte florestal em propriedades rurais fomentadas no estado do Espírito Santo. Revista Árvore, Viçosa, v. 31, n. 3, p. 513-520, 2007.
CORDEIRO, S. A. Desempenho do fomento do órgão florestal de Minas Gerais. 2008. 104p. Dissertação (Mestrado em Ciência Florestal) - Universidade Federal de Viçosa, Viçosa.

FONTES, A. A. Caracterização das propriedades rurais do município de Viçosa/ MG com ênfase na atividade florestal. 2001. 115p. Dissertação (Mestrado em Ciência Florestal) - Universidade Federal de Viçosa, Viçosa.

IEF/MG INSTITUTO ESTADUAL DE FLORESTAS (2007). Fomento florestal. Disponível em: <http://www.ief.mg.gov.br/ index.php?option $=$ com_content\&task $=$ view \&id=58\&Itemid=236> Acesso em: 02 set. 2007.

MATA, H.T.C. Avaliação de demanda residencial rural de lenha como fonte de energia e alternativas de abastecimento por meio de floresta social. 1994. 123p. Dissertação (Mestrado em Ciência Florestal) - Universidade Federal de Viçosa, Viçosa.

OLIVEIRA, P. R. S.; VALVERDE, S. R.; COELHO, F. M. G. Aspectos de relevância econômica no fomento florestal a partir da percepção dos produtores rurais envolvidos. Revista Árvore, Viçosa, v.30 n.4, p. 593-601, 2006.

SIQUEIRA, J. D. P.; LISBOA R.S.; FERREIRA A.M.; SOUZA M.F.R.; ARAÚJO E.; JÚNIOR L.L.; SIQUEIRA M.M. Estudo ambiental para os programas de fomento florestal da Aracruz Celulose S.A. e extensão florestal do Governo do Estado do Espírito Santo. Revista Floresta, Edição Especial, p. 3-67, 2004. 